\title{
Validation Of Phasor Calculations In The Macrodyne PMU For California-Oregon Transmission Project Tests Of March 1993
}

\author{
J. F. Hauer, Fellow \\ Pacific Northwest Laboratories* \\ Richland, Washington 99352
}

\begin{abstract}
Faults applied during March 1993 commissioning tests for the California-Oregon Transmission Project produced $14 \mathrm{~Hz}$ transient oscillations that were conspicuous in BPA's en hanced transducers at Malin, and in PG\&E's Dynamic System Monitor at Table Mountain. Prony analysis of high speed fault data provided a detailed model for the underlying network resonance signal, and a basis for validating transient performance of a Macrodyne Phasor Measurement Unit (PMU) at the test site. This instrument, which is closely associated with EPRI's FACTS project, provides useful insight into emerging technology for high speed digital transducers. The phasor calculations are found to be of very high quality, but filtering enhancements are recommended for broadband applications.
\end{abstract}

Keywords-Phasor measurements, FACTS, feedback control, Prony analysis, network resonances.

\section{INTRODUCTION}

Deployment of fast response control actuators based upon power electronics is sharpening the need for high performance transducers suitable for mission critical applications, both as a source of modulation signals and for detection of anomalous interactions or side effects. Operation of the Celilo HVDC modulation system [1] and the Tacoma Superconducting Magnetic Energy Storage (SMES) unit [2] produced many apparent anomalies that remain unexplained. It is suspected that at least some of them were processing artifacts of the analog transducers used in these projects.

*Manuscript was written while author was employed at the Bonneville Power Administration in Portland, Oregon.

95 SM 444-0 PWRD A paper recommended and approved by the IEEE Power system Instrumentation \& Measurements Committee of the IEEE Power Engineering society for presentation at the 1995 IEEE/PES Summer Meeting, July 23-27, 1995, Portland, OR. Manuscript submitted July 28, 1994; made available for printing June 5, 1995.
Upgrade of the Celilo modulation system, planned for the mid-1980's, would have replaced these with digital transducers employing phasor calculations. Changes in the power system's damping characteristics, plus construction of additional terminals for the Intertie, caused the Modulation Upgrade to be deferred indefinitely. Development of suitable transducers was entrusted to others, in the expectation that the phasor instruments then emerging would evolve in parallel with EPRI's Flexible AC Transmission System (FACTS) project. The Macrodyne Phasor Measurement Unit (PMU) [3-4], with which the Bonneville Power Administration (BPA) has had a long involvement, may soon meet the need. The results presented here represent an ongoing evaluation of the PMU from this standpoint. Much of the material can be applied to phasor instruments in general.

\section{OSCILLATIONS OBSERVED IN THE COTP TESTS OF MARCH 27-28, 1993}

Major fault tests were performed along the new OlindaTracy COTP (California-Oregon Transmission Project) line on March 27 and 28, 1993. Supplemental data was collected on new high resolution monitors (PSAM and PPSM) at BPA's Dittmer control center [5]. Enhanced conventional transducers, with their filtering modified to a bandwidth of roughly $10-12 \mathrm{~Hz}$, were used at Malin to observe test effects upon system dynamics. Bandwidth of the associated communications channels is about $20 \mathrm{~Hz}$.

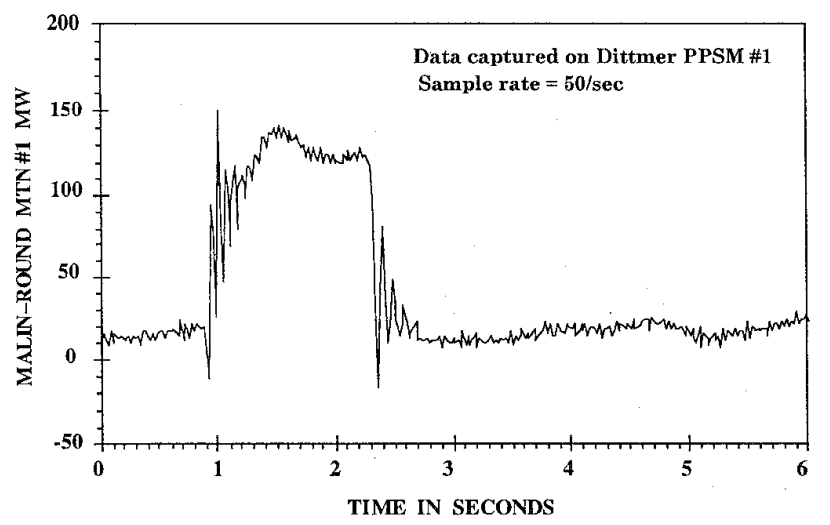

Fig. 1. BPA PPSM record for COTP fault \#3, $03 / 27 / 93(1715 \mathrm{~h})$

U.S. Government Work Not Protected by U.S. Copyright 
Fig. 1 shows PPSM data recorded at 50 samples/sec for COTP Fault \#3, at $1715 \mathrm{~h}$ on $03 / 23 / 93$. The oscillatory transients, at frequencies near $14 \mathrm{~Hz}$, are typical for all enhanced-transducer signals at Malin and for all faults applied. They were not visible through standard transducers, which generally have bandwidths on the . order of $1-2 \mathrm{~Hz}$ and correspondingly narrow band communication channels back to Dittmer.

Inquiries among western utiliites determined that similar data was collected on the Pacific Gas \& Electric (PG\&E) Dynamic System Monitor [6] at Table Mountain, which records at 60 samples/ second and a nominal bandwidth of $30 \mathrm{~Hz}$. High speed fault data, collected on site by the BPA test team, showed these oscillations clearly and demonstrated that they were network oscillations associated with the switching itself (Fig. 2). Prony analysis [7] shows a dominant $37 \mathrm{~Hz}$ peak for all 3 phase currents. The voltage waveforms recovered very quickly, and the oscillations are almost entirely associated with current.

PMU data for this event, collected by Macrodyne and other personnel under contract to the Western Area Power Administration (WAPA), was provided to BPA for analysis. Figs. 3-4 show the corresponding MW signal constructed from the raw phasor table, together with a

A Phase
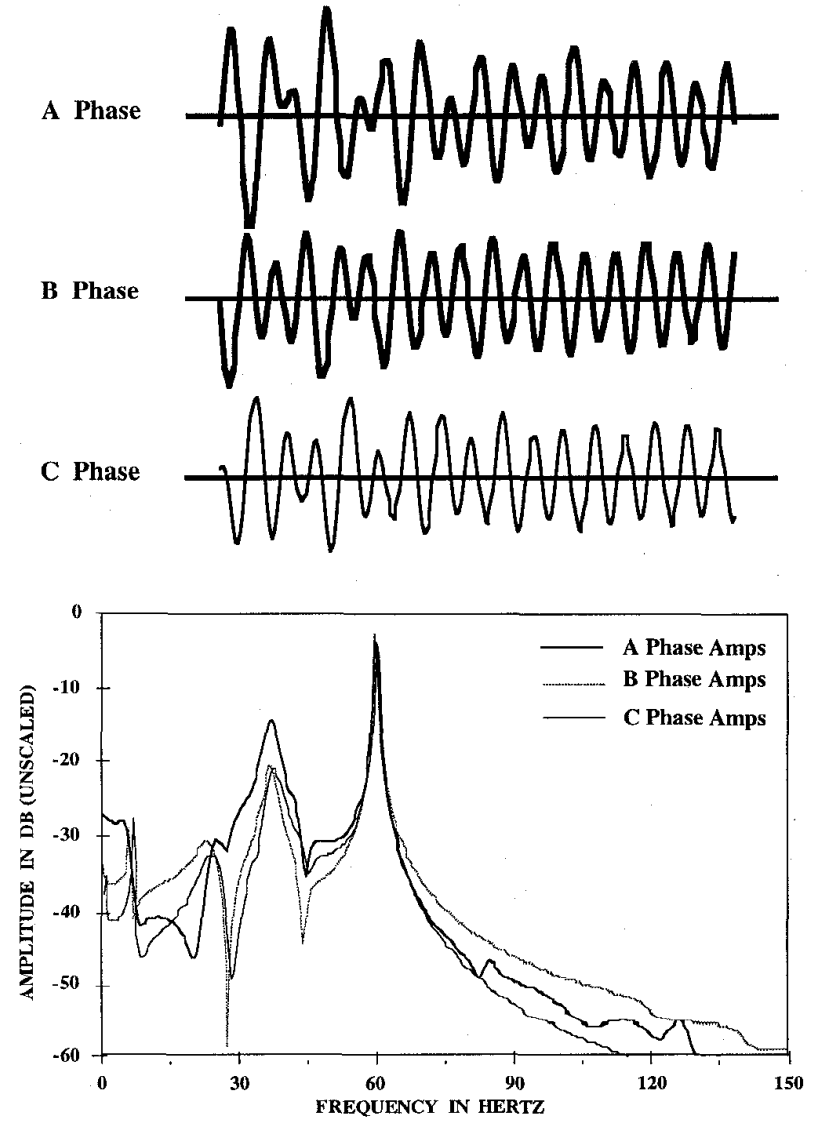

Fig. 2. Signals and Prony spectra for BPA measured current at Olinda substation.
Prony model fitted to it. (Fits including the first oscillation cycle indicated strong nonlinearities and are not shown here.) The spectrum of Fig. 4 and modes of Table $I$ indicate the frequency content of the signal across the analysis interval. Discussion of these results is facilitated by some review of phasor calculations.

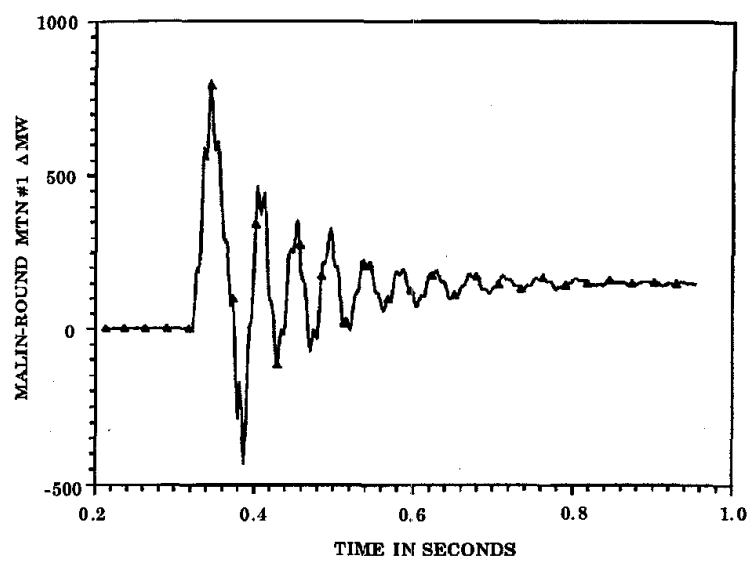

Fig. 3A. Macrodyne PMU record for COTP fault \#3 (constructed from raw phasor table).

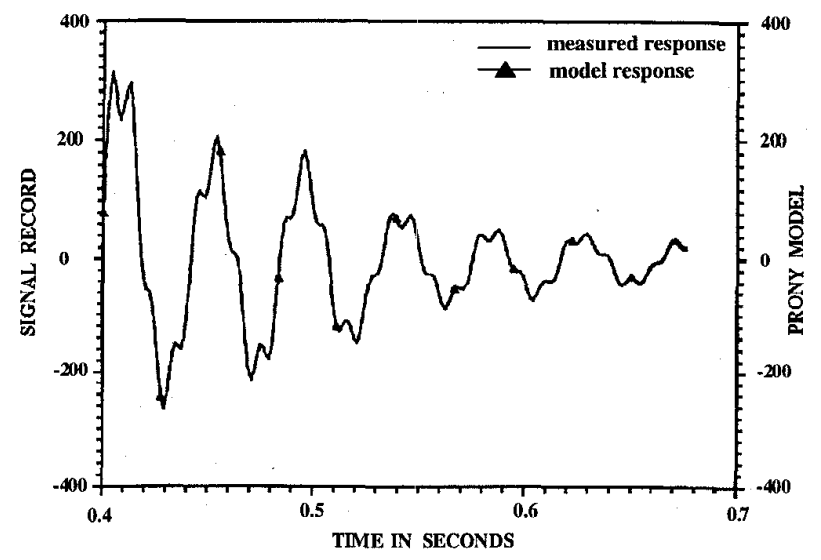

Fig. 3B. Prony fit to Macrodyne PMU record.

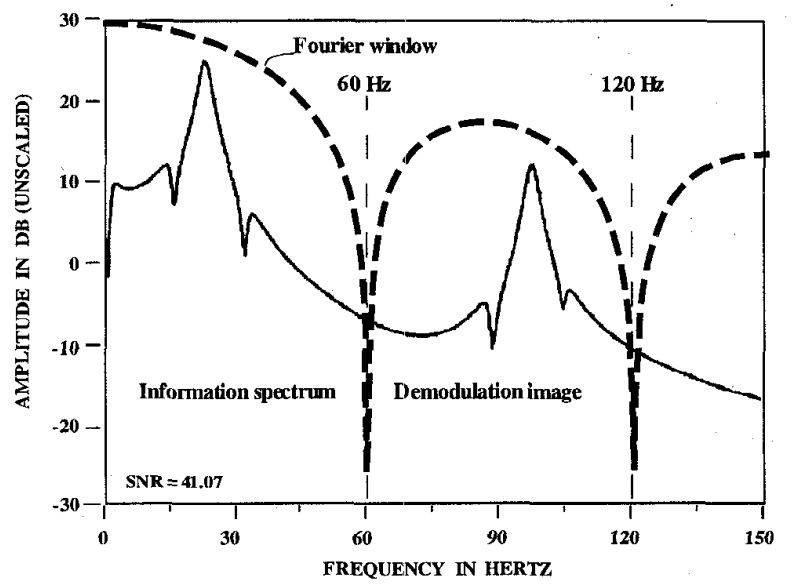

Fig. 4. Prony spectrum for: Macrodyne PMU record 


\begin{tabular}{|c|c|c|c|c|c|c|}
\hline \multicolumn{7}{|r|}{$=0.40$} \\
\hline \multirow{2}{*}{\multicolumn{7}{|c|}{ MODE DAMP FRQ (HZ) REL WT PHASE MAG P }} \\
\hline \multicolumn{4}{|c|}{ 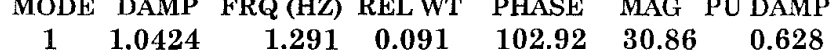 } & & & \\
\hline 2 & & & & & & \\
\hline \multirow{2}{*}{$\begin{array}{l}3 \\
5\end{array}$} & & & & & & \\
\hline & & & & & & \\
\hline \multirow{2}{*}{$\begin{array}{l}12 \\
13\end{array}$} & & & & & & \\
\hline & & & & & & \\
\hline 14 & 1.0827 & 104.574 & 0.013 & -27.04 & 4.5 & 0.010 \\
\hline
\end{tabular}

TABLE I. PRONY SOLUTION TO PMU RECORD.

\section{BASIC PHASOR CALCULATIONS}

Let $v(t)$ and $i(t)$ denote instantaneous voltage and current signals available as transducer inputs. A phasor instrument will extract rms (root mean square) values from these signals by resolving them into components that can be recombined to sharply display the desired information. This usually requires correlation logic that "projects" the signals onto a set of reference waveforms. In a (digital) transducer these would generally be developed from

$$
\begin{aligned}
& S(t)=\sin \left(\omega_{R} t\right) \\
& C(t)=\cos \left(\omega_{R} t\right)
\end{aligned}
$$

Reference frequency $\omega_{R}$ might be the nominal value for the actual frequency $\omega_{n}$, or it might be an estimate for $\omega_{n}$ that is developed during the measurement process itself. For three phase calculations $\mathrm{v}(\mathrm{t})$ and $\mathrm{i}(\mathrm{t})$ become vectors. So do the reference waveforms, which are extended to include sines and cosines displaced by \pm 120 degrees.

The concepts involved are exactly those underlying Fourier analysis and the demodulation of amplitude modulated radio signals. The basic principles can be demonstrated through single-phase calculations. Define

$$
\begin{aligned}
& \mathrm{i}_{\mathrm{s}}(\mathrm{t})=\langle\mathrm{i}(\tau), \mathrm{S}(\tau)\rangle_{\mathrm{w}} \equiv \operatorname{Avg}_{\mathrm{w}}\{\mathrm{i}(\tau) \mathrm{S}(\tau)\} \\
& \mathrm{i}_{\mathrm{c}}(\mathrm{t})=\langle\mathrm{i}(\tau), \mathrm{C}(\tau)\rangle_{\mathrm{w}} \equiv \operatorname{Avg}_{\mathrm{w}}\{\mathrm{i}(\tau) \mathrm{C}(\tau)\}
\end{aligned}
$$

Here $\langle\bullet, \bullet\rangle_{\mathrm{w}}$ indicates the projection of one signal onto another, and $\operatorname{Avg}_{W}\{\bullet\}$ indicates some averaging process. Both operations are performed with $\tau$ ranging across some window $W$. This window defines the length of the averaging process, the data to be processed at time $t$, and the filter weights to be used in forming the average.

Consider the case

$$
\begin{aligned}
& \omega_{\mathrm{R}}=\omega_{\mathrm{n}} \\
& \mathrm{i}(\mathrm{t})=\mathrm{i}_{0}(\mathrm{t})=\mathrm{I}_{0} \sin \left(\omega_{\mathrm{n}} \mathrm{t}+\theta\right)
\end{aligned}
$$

for which

$$
\begin{aligned}
i(t) S(t) & =I_{0} \sin \left(\omega_{n} t+\theta\right) \sin \left(\omega_{n} t\right) \\
& =\frac{1}{2} I_{0}\left[\cos (\theta)-\cos \left(2 \omega_{n} t+\theta\right)\right]
\end{aligned}
$$

Suppose too that $W$ produces an exact, uniformly weighted average across one cycle of $S(t)$ and introduces a scale factor of 2 . Then

$$
\begin{aligned}
& i_{s}(t)=\operatorname{Avg}_{w}\{I(t) S(t)\}=I_{0} \cos (\theta) \\
& i_{c}(t)=\operatorname{Avg}_{w}\{I(t) C(t)\}=I_{0} \sin (\theta)
\end{aligned}
$$

Now $i(t)$ can be described by the complex variable

$$
\overrightarrow{\mathrm{i}}(\mathrm{t})=\mathrm{i}_{\mathrm{s}}(\mathrm{t})+\mathrm{ji}_{\mathrm{c}}(\mathrm{t})=\mathrm{I}_{0}[\sin (\theta)+\mathrm{j} \cos (\theta)]=\mathrm{I}_{0} \angle \theta
$$

where $j=\sqrt{-1}$. In power system applications $\vec{i}(t)$ is usually termed a phasor, or more specifically, a current phasor. The associated voltage phasor $\vec{v}(t)$ can be formed in a similar manner, and combined with $\vec{i}(t)$ to determine other quantities such as real or reactive power.

The example here is rather idealized, in that $\omega_{R}$ exactly equaled $\omega_{\mathrm{n}}$ and the averaging process exactly eliminated the double frequency term at $2 \omega_{n}$. A practical instrument must deliver good performance without such exactitude, which requires close attention to signal processing details.

\section{FOURIER WINDOWING IN THE PMU}

Fourier calculations in the Macrodyne PMU employ a 1 cycle uniform average, or "boxcar" filter. Its gain response, shown in Fig. 5 with sampling effects omitted, has a basic $\sin (x) / x$ structure. Its effects are clearly evident in Fig. 4, where the symmetry about $60 \mathrm{~Hz}$ follows from equation (2) and the fundamental identities

$$
\begin{aligned}
& \sin (x) \sin (y)=\frac{1}{2}[\cos (x-y)-\cos (x+y)] \\
& \sin (x) \cos (y)=\frac{1}{2}[\sin (x-y)+\sin (x+y)]
\end{aligned}
$$

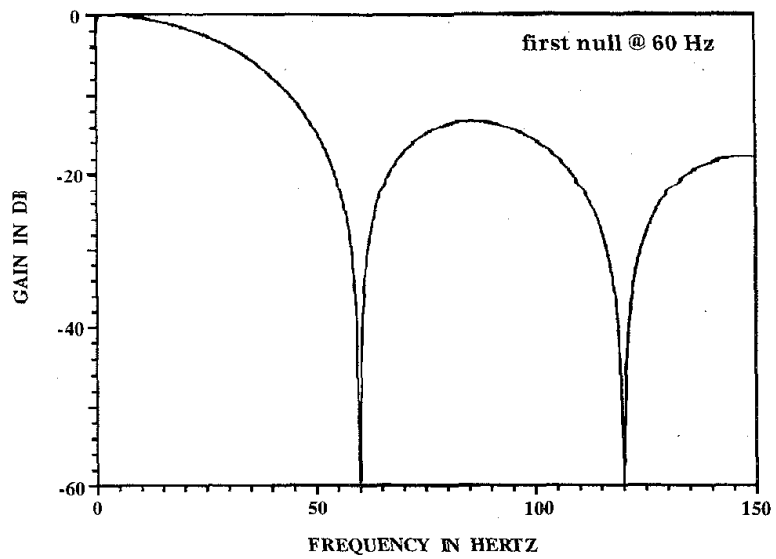

Fig. 5. Filtering for 1 cycle uniform averaging 
The demodulation image in Fig. 4, above $60 \mathrm{~Hz}$, is associated with the upper sideband $x+y$ in these relations. Amplitude modulation of the $60 \mathrm{~Hz}$ carrier obeys similar mathematics. As the signal spectrum in Fig. 2 is one-sided about $60 \mathrm{~Hz}$, it represents additive rather than modulating dynamics. Thus the lower sideband $x-y$ of $(8 \mathrm{~A})$ maps each frequency of the true oscillation spectrum to its $60 \mathrm{~Hz}$ complement. Note, for example, that the dominant peak near $37 \mathrm{~Hz}$ in the phase current spectrum of Fig. 2 produces the major peaks near $60-37=23 \mathrm{~Hz}$ and $60+37=97 \mathrm{~Hz}$ in Fig. 4 .

Figs. 6-7 show corresponding MW data based upon positive sequence phasor calculations and the data of Fig. 2. Differences between these results and those for the PMU should be expected: the BPA recordings involved a different voltage sensor, different filtering, 12 bit digitization, and 200,000 samples/second acquisition decimated to roughly 714 samples/second. Even with these differences the agreement between BPA and Macrodyne results is quite good.

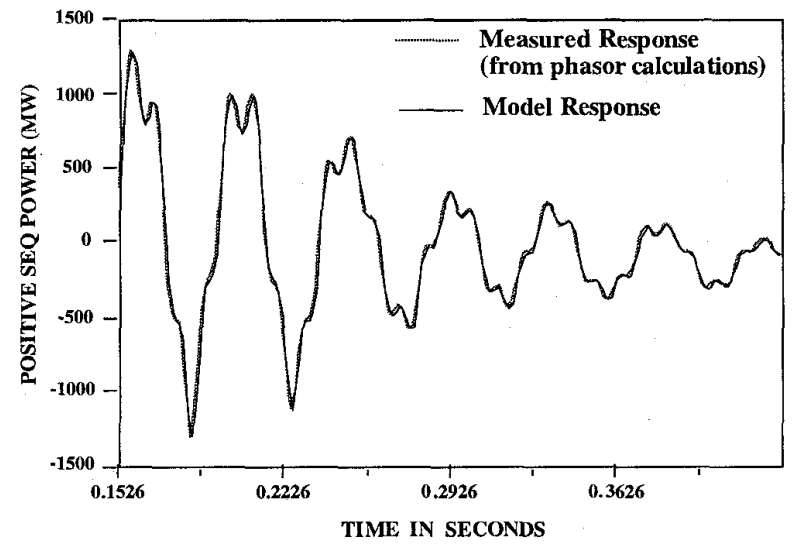

Fig. 6. Prony fit to positive sequence MW (BPA data at Olinda substation) COTP fault \#3, 03/27/93 (1715 h)

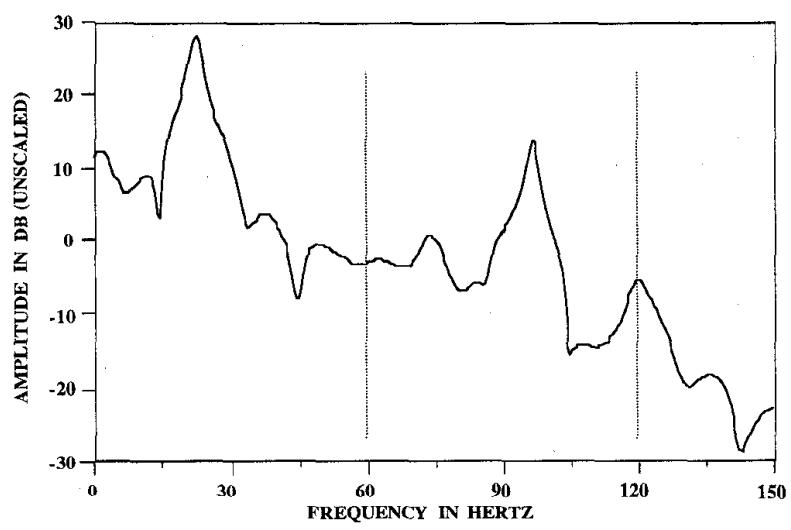

Fig. 7. Prony spectrum for positive sequence MW (BPA data at Olinda substation). COTP fault \#3, 03/27/93 (1715 h)

\section{OUTPUT FILTERING IN THE PMU}

Fig. 5 indicates that response for the Fourier filter is zero at integer multiples of $60 \mathrm{~Hz}$, but falls off very slowly at the intervening sidelobes. If signal products such as $\mathrm{i}(\tau) \mathrm{S}(\tau)$, from equation (6), contain broadband components there is a strong likelihood that they will pass through this filter into the raw phasor table.

Raw phasors are calculated at the rate of 12 per cycle, or 720 per second, for each output channel. At present these are averaged together across $\mathrm{N}$ cycles and delivered from the PMU at a rate of $60 / \mathrm{N}$ per second. Permitted values of $\mathrm{N}$ are 2, 5, and 10. Analogous to Fig. 5, the first nulls for these averaging filters are located at $30 \mathrm{~Hz}, 12 \mathrm{~Hz}$, and $6 \mathrm{~Hz}$ respectively. These approximate bandwidths equal the output sample rate, or twice the Nyquist frequency.

There are at least two potential problems with the signal processing described above:

- Overall filtering may not sufficiently suppress extraneous signals such as the demodulation sidebands associated with equation (2).

- Decimation of the raw phasors is not sufficiently protected against aliasing.

These may raise no difficulties under "narrow band" conditions, when all signals are near some integer multiple of $60 \mathrm{~Hz}$. However, as the following examples demonstrate, PMU filtering needs enhancement to fully accommodate broadband signals.

Figs. $8 \mathrm{~A}-\mathrm{C}$ show the spectra obtained by processing the Fig. 4 PMU record through various output filters. Filter transients and decimation effects are not included. The $97 \mathrm{~Hz}$ peak in Fig. $8 \mathrm{~A}$ is about $24 \mathrm{db}$ below the main $(23 \mathrm{~Hz})$ peak, and thus has a relative strength of roughly $6 \%$. Since the data stream is subsequently decimated to 30 samples/second, this signal component will be aliased to a frequency of ( 97 modulo 30$)=7 \mathrm{~Hz}$. There it is $20 \mathrm{db}$ below the true spectrum and, depending upon phase relations, can produce a local change ranging to $\pm 10 \%(0.83 \mathrm{db})$. While this effect is small, it is compounded by every frequency component that aliases to $7 \mathrm{~Hz}$. For the present sample rate, these are given by $\mathrm{f}_{7}=30 \mathrm{M} \pm 7$ as $\mathrm{M}$ ranges across the positive integers. Specifically, $\mathrm{f}_{7}=23,37,53,67,83,97, \ldots$ This includes the dominant $23 \mathrm{~Hz}$ peak itself, which of course is beyond the $15 \mathrm{~Hz}$ Nyquist frequency.

Fig. $8 \mathrm{~B}$ shows that the situation does not improve much with 5 cycle averaging. Fig. $8 \mathrm{C}$ suggests somewhat better results for a pair of 2-cycle averaging filters in series (or one 4-cycle triangular filter), provided that the output sample rate is increased. At this level of complexity a recursive lowpass filter might be preferable. 


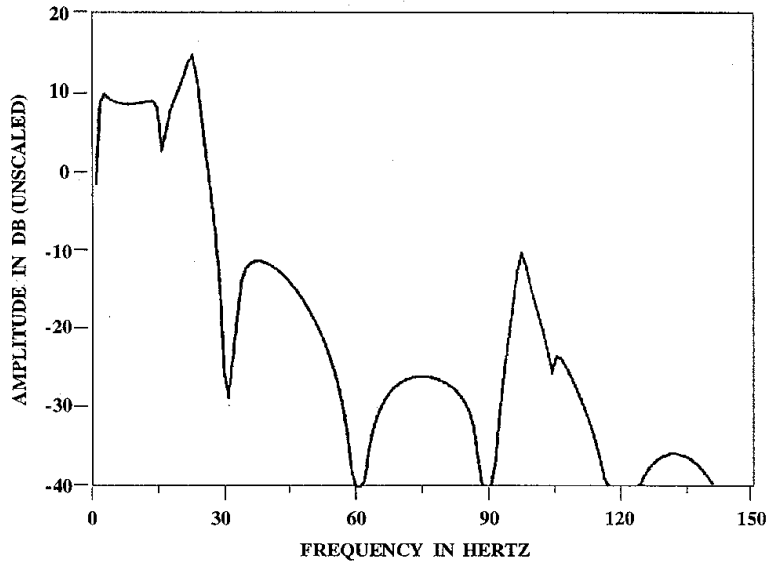

Fig. 8A. PMU output spectrum for 2 cycle uniform averaging

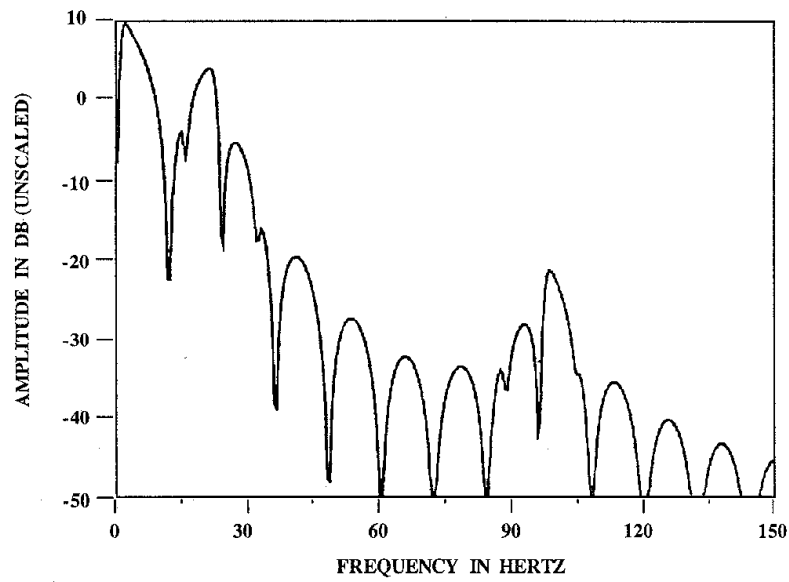

Fig. 8B. PMU output spectrum for 5 cycle uniform averaging

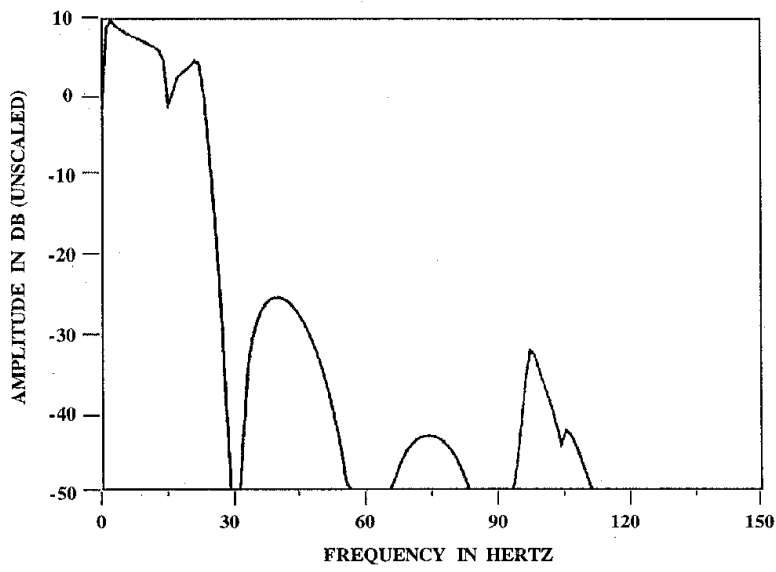

Fig. 8C. PMU output spectrum for 2 cycle uniform averaging, done twice

\section{CONCLUSIONS}

The generic technology represented in the Macrodyne PMU provides the basis for an excellent digital transducer. It brings the added benefits of phase angle data, overall reliability, and emerging standards for continuing development and support. The PMU itself was not developed within the requirements framework of a fully programmable instrument package, however [5], and some potential features could not be added onboard without substantial redesign. Some of these would detract from its primary functions and are best sought through an accessory computer, analogous to those used with high performance digital fault recorders.

Clearly, though, some applications will call for a sharper match between filtering and sample rate. To any who might argue that a $37 \mathrm{~Hz}$ network oscillation is too rare an event to worry about, consider that a 23 $\mathrm{Hz}$ oscillation on a generator shaft would produce very similar results over a much longer time. A fully evolved instrument should either ignore such activity or else depict it accurately.

A further consideration is the risk that feedback control of power electronics equipment may modulate a second harmonic carrier (or, worse yet, some nonharmonic carrier). The most straightforward precaution against mistaking information on the second harmonic for that on the first harmonic is protective filtering of voltage and current signals before their phasors or other rms quantities are calculated (see Fig. A in the Appendix). This probably limits the information bandwidth to not more that $30 \mathrm{~Hz}$, which may also be the practical limit for any rms transducer installed on a $60 \mathrm{~Hz}$ power system. Approaching or surpassing this bandwidth will demand very close attention to signal processing details.

These details are not yet completely known for the transducers through which the $14 \mathrm{~Hz}$ oscillations of Fig. 1 were first observed. Work in progress may well link these to the $15 \mathrm{~Hz}$ sidelobe term in Table I. Whatever the mechanism, the incident demonstrates that transducer response must be factored into control law design for high performance applications.

\section{ACKNOWLEDGMENT}

The author extends his sincere thanks to WAPA for the sharing of PMU test data, to the BPA test team for their assistance in reconstructing test activities, and to Jay Murphy (president of Macrodyne, Inc.) for many interesting discussions of measurement technology. Thanks are also due the Reviewers, for suggestions that refined the paper markedly.

\section{REFERENCES}

[1] J. F. Hauer, "Reactive Power Control as a Means for Enhanced Interarea Damping in the Western U. S. Power System-A Frequency-Domain Perspective Considering Robustness Needs," Application of Static Var Systems for System Dynamic Performance, IEEE Publication 87TH0187-5-PWR, pp. 79-92. 
[2] J. F. Hauer and H. J. Boenig, "Control Aspects of the Tacoma Superconducting Magnetic Energy Storage Project," IEEE Trans. Power Systems, Vol. PWRS-2, pp. 443-450, May 1987.

[3] K. Martin, Phasor Measurement System Test," Proc. BPA 1992 Engineering Symposium, Portland, OR, March 31-April 1, pp. 689-704.

[4] A. G. Phadke, "Synchronized Phasor Measurements in Power Systems," IEEE Computer Applications in Power Systems, pp. 10-15, April 1993.

[5] J. F. Hauer, "An Applications Perspective on Advanced Measurement Technology in Wide Area Monitoring and Control," Third Virginia Tech Conference on
Computers in Electric Power Engineering, Arlington, VA, October 27-29, 1993.

[6] H. K. Clark, R. K. Gupta, C. Loutan, and D. R. Sutphin, "Experience with Dynamic System Monitors to Enhance System Stability Analysis," IEEE Trans. Power Systems, Vol. PWRS-7, pp. 693-701, May 1992.

[7] J. F. Hauer, "Application of Prony Analysis to the Determination of Modal Content and Equivalent Models for Measured Power System Response," IEEE Trans. Power Systems, Vol. PWRS-6, pp. 1062-1068, August 1991.

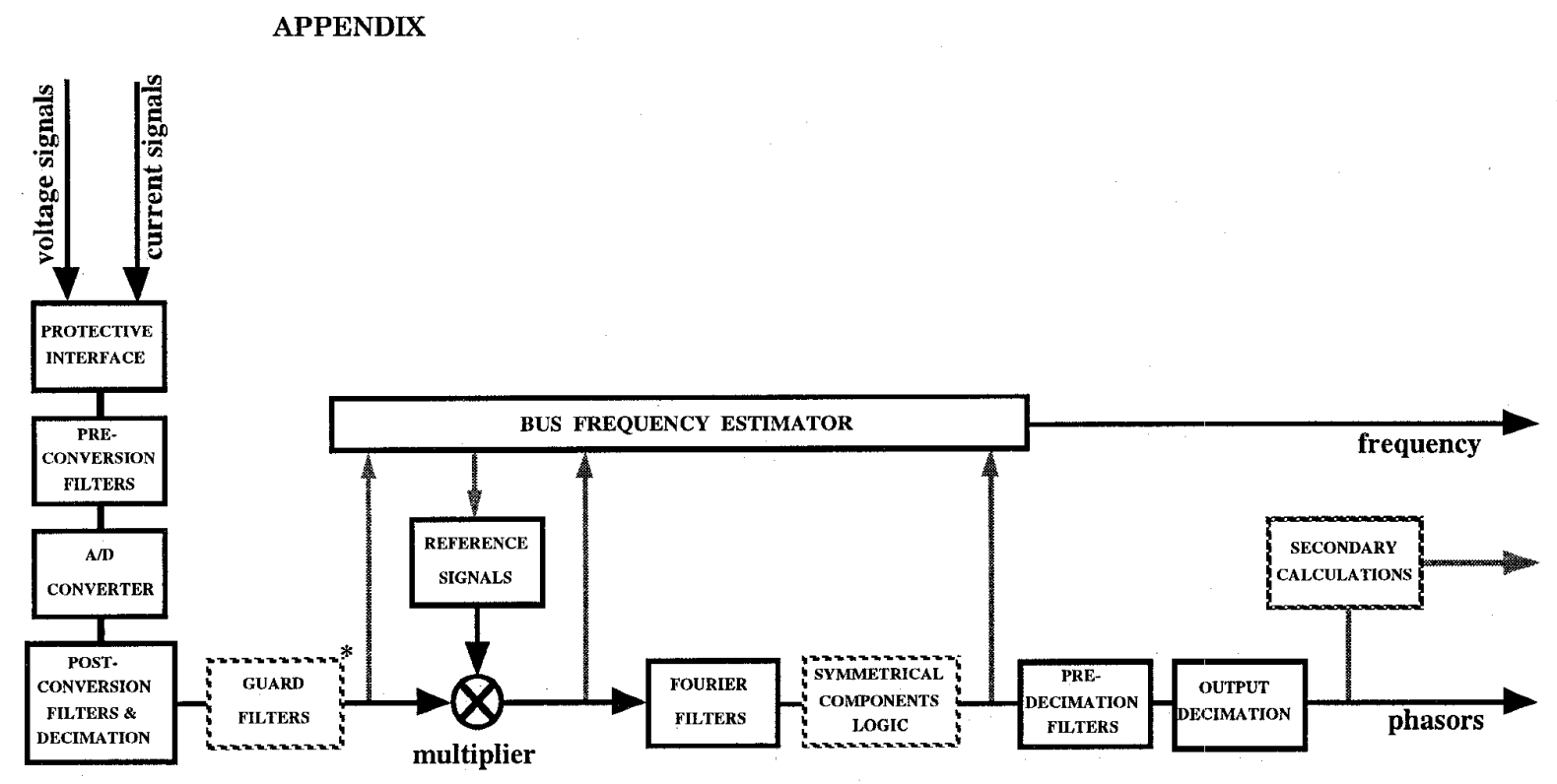

(*Grey shading indicates optional element)

Fig. A. General architecture for a digital transducer set

The functional organization indicated in Fig. A is broadly representative of transducers based upon phasor calculations. The structure provides several points where bus frequency can be estimated, and it permits use of this estimate to adjust the reference signals upon which voltage and current signals are projected. Among the other optional features the guard filters warrant special mention. While their function might actually be absorbed into the post-conversion or the Fourier filtering, the appropriate settings may change with the application. This is particularly likely in high performance stability control, where both the control law and the monitoring equipment should be well protected against spurious activity. The ability to do this readily and precisely is a major advantage of the emerging digital transducer technology.

\section{BIOGRAPHY}

John F. Hauer (F' '90) was born in 1936 in Colville, Washington. He achieved his Bachelors degree at Gonzaga University, in 1961, and his Ph.D. degree at the University of Washington in 1968. Both are in electrical engineering. Prior to graduate studies he worked with the General Electric Company, in the area of nuclear reactor controls, and developed spacecraft navigation and guidance methods at the Boeing Company. From 1968 to 1975 he was a member of the Computing Science faculty at the University of Alberta, with activities centered upon constrained optimization of dynamic systems. In 1994 he stepped down as Principal Engineer for Power System Dynamics at the Bonneville Power Administration, where he has served since 1975, and assumed similar duties at Battelle, Pacific Northwest Laboratories. Dr. Hauer is a member of the Power Engineering and Control System Societies. 


\section{Discussion}

R. E. Wilson (Western Area Power Administration, Montrose, $\mathrm{CO}$ ): The author is to be complimented in producing a study partially verifying this new instrument. The verification is important because researchers are considering using this or similar instruments in future power system control applications. I enjoyed reading about additional uses of the data obtained from the staged fault testing and collected under a contract between Western Area Power Administration and the University of Wyoming with the discusser as Principal Investigator. Following are a few minor comments, some questions, and issues for consideration by the author.

The caption under Figure $3 \mathrm{~A}$ states the figure was generated from raw phasor data. The measuring unit under discussion records A-B-C voltage or current phase data which is often called raw channel data. As noted, the unit also records positive sequence data. Did the author generate Figure $3 \mathrm{~A}$ directly from the raw channel data and then do the power flow calculation for the time-series of data, or did he use the instruments built-in positive sequence phasor transformation to calculate the watts shown?

Did the author attempt to identify various spectral peaks and valleys as shown in several figures with power system effects? A previous work has identified several peaks and valleys produced by a simple Fourier analysis of the data [1]. The identified responses corresponded to simple resonances between various line sections and the several set of series capacitors.

Has the author verified other aspects of the measurement unit? The basic phase angle measurement technique has received preliminary verification and was presented in a panel discussion at the 1993 IEEE Summer Power Meeting, as summarized by Schulz [2]. Further analysis have verified the phase angle measurement technique with an average value of -0.09 degree over a set of eight observations [3].

The author discusses signal processing within the measuring unit in Section V. I am unclear of the severity of the problem. What should present owners be aware of? Is a solution available? Could any solution be implemented by a software revision from the manufacturer or the author?

I was present during the staged fault testing and noticed that Bonneville Power Administration installed some precision high-voltage instrument transformers. Were any comparisons made between the responses of the precision and standard instrument transformers?

In summary, the author is to be commended for producing work that adds confidence for practicing and research engineers using this new measuring instrument.

\section{References:}

1. R.E. Wilson, P.S. Sterlina, "GPS Synchronized Power
System Phase Angle Measurements," International Journal of Satellite Communications, Vol 12, No. 5, September-October, 1994, pp. 499-505.

2. R.P. Schulz, "Summary of Presentations from the Panel Sessions 'Applications and Experience in Power System Monitoring with Phasor Measurements,'" Conference on Precise Measurements in Power Systems, October 27-29, 1993, Arlington, VA.

3. R.E. Wilson, P.S. Sterlina, "Verification of Measured Transmission System Phase Angles," submitted to IEEE PES Winter 1996 Meeting.

Manuscript received August 28, 1995.

J. F. Hauer: The comments of the Dr. Wilson are very welcome.

With respect to Fig. 3A, the signal there was constructed from the PMU "one second table" for (positive sequence) phasor voltage and current. In the framework of .Fig. A, these phasors are taken at the output of the symmetrical components logic. This table provides a snapshot of the raw phasors that are filtered and decimated to yield the eventual phasor outputs.

The development establishes that the $97 \mathrm{~Hz}$ ripples in Figs. 3 are signal processing artifacts, associated with a demodulation image that the present Fourier filter will not always remove adequately. Thus the raw phasors should be interpreted cautiously, and the advanced user may choose to apply custom filtering external to the PMU.

The spectral features to which the Dr. Wilson refers are typical for fault tests performed on the Pacific AC Intertie, and for large scale simulations of such tests performed with the Electromagnetic Transients Program (EMTP). These features are very test specific, and should provide a good basis for model validation if this is needed. I am not aware of any specific efforts along these lines, with the possible exception of Dr. Wilson's Ref. [1]. I have had no opportunity to examine this work as yet, but I do entertain mild reservations concerning the general ability of Fourier analysis to yield sharp results for brief transients associated with large carriers.

Phase angle measurements are certainly a defining capability of PMU technology. In addition to Dr. Wilson's work in this area, the broader aspects of PMU performance are being examined at the BPA Division of Laboratories and within a DOE sponsored demonstration project for wide area measurement systems [C1].

Any signal processing shortfalls that may be present in the PMU can certainly be remedied through software adjustments. This is largely a matter of "value engineering" the product, to achieve good balances between costs, technical performance, and general usefulness. At present this translates into trades among stronger filtering, lower bandwidth, fewer channels, and a more expensive CPU-all compounded by a rapidly evolving application environment. 


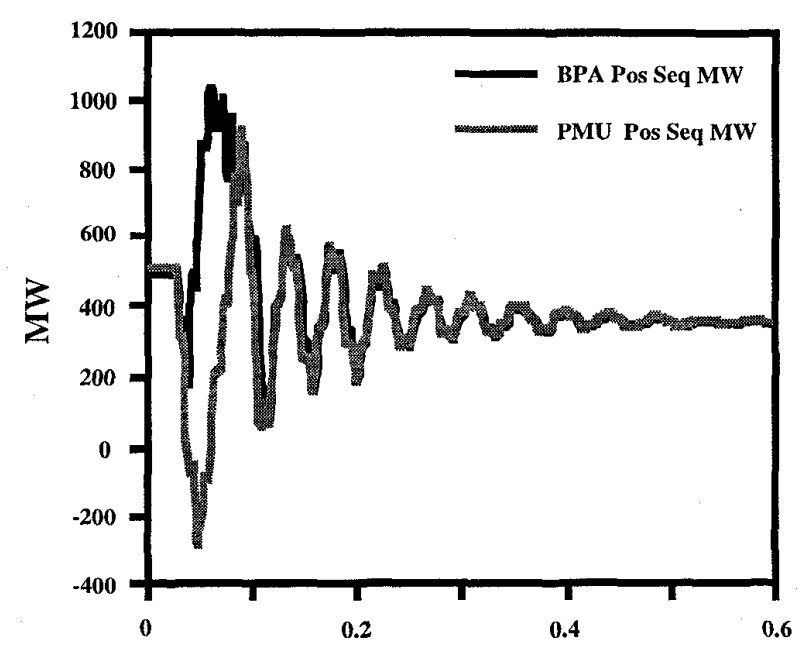

Time in Seconds

Fig. C1. PMU vs. BPA fault data, COTP Fault \#5

This paper has demonstrated two specific problems: incomplete removal of the demodulation image, and excessive bandwidth in the later pre-decimation filter,. Whether this translates into one filtering problem, or two of them, depends upon the signal quality required in the raw phasor table. My expectation is that something better than linear averages will be provided before long.

Concerning the instrument transformers, my impression is that these were commercial precision voltage dividers [C2]. These were of two types, both accurate within $\pm 1 \%$, for frequencies from 0 to $1 \mathrm{MHz}$ and 0 to $4 \mathrm{MHz}$ respectively. The PMU was not connected to these devices, but to standard CCVT (capacitor coupled voltage transformer) units. As shown in Fig. $\mathrm{C}$, initial portions of the PMU measurement in Fig. 3A differs from phasor calculations performed on BPA fault data. It is possible that much of this is due to CCVT effects.

[C1] W. A. Mittelstadt, P. E. Krause, P. N. Overholt, J. F. Hauer, R. E. Wilson, and D. T. Rizy, "The DOE Wide Area Measurement System (WAMS) Project Demonstration of Dynamic Information Technology for the Future Power System," 1995 Fault and Disturbance Analysis/Precise Measurements in Power Systems Conference, Arlington, VA, November 8-10, 1995.

[C2] S. H. Sarkinen et. al., "COTP Staged Fault Tests," BPA Laboratory Report ELE-93-39, June 17, 1993.

Manuscript received October 16, 1995. 